\title{
АКТИВНОСТЬ ЗЕМЕЛЬНЫХ РЕСУРСОВ ПО СТРАНАМ
}

П.М. Мазуркин, д-р техн. наук, проф., акад. РАЕ и РАЕН, член Европейской академии естествознания, kaf_po@mail.ru, Поволжский государственный технологический университет, Йошкар-Ола

Аннотация На примере глобального агроэкологического зонирования (GAEZ) 160 стран по состоянию на 2002 г. рассмотрены четыре уровня земельных ограничений. Активность равна проценту от общей площади территории страны, а за объясняющую переменную принимается площадь каждого земельного ограничения. Показаны пятичленные статистические модели распределений 160 стран по земельным ограничениям с волновыми составляющими с переменной амплитудой и периодом колебаний. По моделям выполнена проверка адекватности классификации земельных ресурсов.

Ключевые слова: земельные ограничения, проверка классификации, 160 стран, распределения, закономерности.

\section{ACTIVITY OF LAND RESOURCES OVER THE COUNTRIES P.M. Mazurkin}

Doctor of Engineering Science, Academician of RANS, member of EANS, Volga State University of Technology, Yoshkar-Ola, Russia, kaf_po@mail.ru

Abstract. On the example of global agro-ecological zoning (GAEZ) of 160 countries as of 2002 four levels of land restrictions are considered. Activity is equal to percent from the total area of the territory of the country, and the area of each land restriction is accepted to explaining variable. Five-membered statistical models of distributions of 160 countries on land restrictions with wave components with a variable amplitude and the period of fluctuations are shown. On models check of adequacy of classification of land resources is executed.

Keywords: land restrictions, classification check, 160 countries, distributions, regularities.

Введение. В мировой практике оценки земельных ресурсов существуют глобальные агроэкологические зоны (GAEZ), которые дают стройные картины распределения.

Методология AEZ для оценки продуктивности земель исходит из экологического подхода и обеспечивает основу для создания пространственной инвентаризации и базы данных земельных ресурсов для сельскохозяйственного производства. Характеристика земельных ресурсов включает в себя компоненты климата, почвы, рельефа и текущий растительный покров. Адекватное сельскохозяйственная эксплуатация земель и поддержание их продуктивности во многом зависят от управления почвами на экологически устойчивой основе [1].

В документе [1] отмечено, что за последние 20 лет термин «агроэкологические зоны», или AEZ, стал широко использоваться. Это было связано с широким спектром различных мероприятий, часто совершенно разных по своим масштабам и целям.

ФАО и ИИАСА дифференцируют методику AEZ в следующих мероприятиях:

- во-nервых, AEZ обеспечивает стандартизированную структуру для характеристики климата, почвы и условий местности, имеющих отношение к сельскохозяйственной продукции. В этом контексте понятие «длина вегетационного периода» применено в картографических измерениях, направленных на зонирование в различных масштабах, от субнациональных до глобального уровня;

- во-вторых, процедуры согласования AEZ используются для идентификации культур конкретных ограничений по атмосфере, почве и ресурсов местности, под при- 
нятыми уровнями входов и условий хозяйствования: эта часть методологии AEZ дает оценки максимально возможной и агрономические достижимые урожайности для базовых значений земельных ресурсов;

- в-третьих, AEZ обеспечивает рамки для различных применений: предыдущие два комплекта деятельности привели к очень большим базам данных. Информация, содержащаяся в наборах данных, формируют основу для ряда приложений AEZ, таких как количественной оценки продуктивности земель, продуктивности с богарных или орошаемых земель, оценки населения по способности земли к восстановлению, и по множеству критериев оптимизации использование и развитие земельных ресурсов.

Методология AEZ использует данные инвентаризации земельных ресурсов для оценки при заданных условиях управления и уровней входов, возможных сельскохозяйственных вариантов землепользования и количественно ожидаемое производство земледельческой деятельности. Характеристика земельных ресурсов включает в себя компоненты климата, почв и рельефа.

Наличие цифровых глобальных баз данных климатических параметров, почвы и рельефа, а также почвенно-растительного покрова, позволило изменить и улучшить процедуры расчета. Это также позволило расширить оценки AEZ урожайности, пригодности и производительности потенциалов земель на умеренных и бореальных средах, что позволяет эффективно проводить глобальный охват для оценки сельскохозяйственных потенциалов.

B AEZ методологии процедуры были расширены и на цифровые географические базы данных для того, чтобы справиться с конкретными характеристиками сезонных умеренных и бореальных климатических условий. В отчете [1] описаны методологические приспособления, необходимые для глобальной оценки и иллюстрации многочисленных результатов по широкому спектру применения

Метод идентификации. Наш метод предполагает достоверность исходных цифровых данных. Он был разработан на более чем 100 тысяч примеров статистического моделирования. В частности, методология была применена для анализа сельскохозяйственного производства в сельских районов Татарстана $[2,4,16]$, коррелятивной вариации биохимических параметров почвы [8], распределения земельного фонда Республики Чувашия [15] и Республики Марий Эл $[17,19]$. Биологический каркас территории по площади земель подробно рассмотрен в публикациях $[3,5,9-11,13,14,18]$.

Математический подход к статистическому моделированию устойчивыми волновыми закономерностями показан в публикациях $[6,7,12,20]$.

Любой процесс можно идентифицировать суммой вейвлет-сигналов вида

$$
\begin{array}{r}
y_{i}=A_{i} \cos \left(\pi x / p_{i}-a_{8 i}\right), \\
A_{i}=a_{1 i} x^{a_{2 i}} \exp \left(-a_{3 i} x^{a_{4 i}}\right), p_{i}=a_{5 i}+a_{6 i} x^{a_{7 i}},
\end{array}
$$

где $A_{i}$ - амплитуда (половина) вейвлета (ось $y$ ), $p_{i}$ - полупериод волны (ось $x$ ), $i$ номер составляющей статистической модели, $a_{1} \ldots a_{8}$ - параметры модели, вычисляемые в программной среде CurveExpert (URL: http://www.curveexpert.net/).

По формуле (1) с двумя фундаментальными физическими постоянными $e$ (число Непера или число времени) и $\pi$ (число Архимеда или число пространства) образуется изнутри изучаемого явления и/или процесса квантованный вейвлет-сигнал.

Понятие асимметричного вейвлет-сигнала позволяет абстрагироваться от физического смысла самих рядов чисел [1], и рассматривать их аддитивное разложение.

Исходные данные. Как пример статистического моделирования покажем наш метод идентификации на массиве data1.xls [1] по распределению 160 стран. В таблице 1 даны следующие обозначения: CTR (коды стран); REG (коды регионов).

Отношение площади уровня ограничения к общей площади мы называем активностью влияния фактора, в нашем примере активностью площади земельных ограничений на долю этих ограничений от общей площади страны. 
Таблица 1

Земельные ограничения на богарных производствах сельскохозяйственных культур (160 стран)

\begin{tabular}{|c|c|c|c|c|c|c|c|}
\hline \multirow[b]{2}{*}{ CTR } & \multirow[b]{2}{*}{ REG } & \multirow[b]{2}{*}{$\begin{array}{c}\text { Наименование } \\
\text { страны }\end{array}$} & \multirow{2}{*}{$\begin{array}{c}\text { Общая } \\
\text { площадь, } \\
1000 \text { га }\end{array}$} & \multicolumn{4}{|c|}{ Уровень ограничений, \% от общей площади } \\
\hline & & & & $\begin{array}{c}\text { нет } \\
\text { ограни- } \\
\text { чения }\end{array}$ & $\begin{array}{c}\text { умеренное или } \\
\text { небольшое } \\
\text { ограничение }\end{array}$ & $\begin{array}{c}\text { ограничения } \\
\text { по тяжелому } \\
\text { климату }\end{array}$ & $\begin{array}{c}\text { ограничения } \\
\text { по тяжелой } \\
\text { почве +местности }\end{array}$ \\
\hline 33 & 11 & CANADA & 978404 & 0,6 & 6,0 & 50,5 & 42,8 \\
\hline 231 & 11 & UNITED STATES & 946837 & 8,4 & 15,2 & 37,0 & 31,4 \\
\hline 27 & 21 & BULGARIA & 11057 & 22,0 & 40,2 & 0,0 & 37,7 \\
\hline 57 & 21 & BELARUS & 20615 & 0,5 & 59,6 & 0,0 & 39,9 \\
\hline 97 & 21 & HUNGARY & 9213 & 25,5 & 27,3 & 0,0 & 47,3 \\
\hline$\ldots$ & $\ldots$ & $\ldots$ & $\ldots$ & $\ldots$ & $\ldots$ & $\ldots$ & $\ldots$ \\
\hline
\end{tabular}

Таким образом, уровень ограничений по активности равен проценту от общей площади территории страны. При этом уровни ограничений можно расставить по вектору «лучше $\rightarrow$ хуже» по следующим кодам: 1 - нет земельного ограничения; 2 - умеренное или небольшое земельное ограничение; 3 - земельные ограничения возникают из-за тяжелого климата; 4 - земельные ограничения от тяжелой почвы и местности.

Выбор абсциссы. Для установления закономерности распределения 160 стран по уровням земельных ограничений необходима какая-то шкала абсцисс.

Вначале примем за ось абсцисс значения общей площади страны.

С учетом кода уровня земельных ограничений пространственный график распределения показан на рисунке 1.

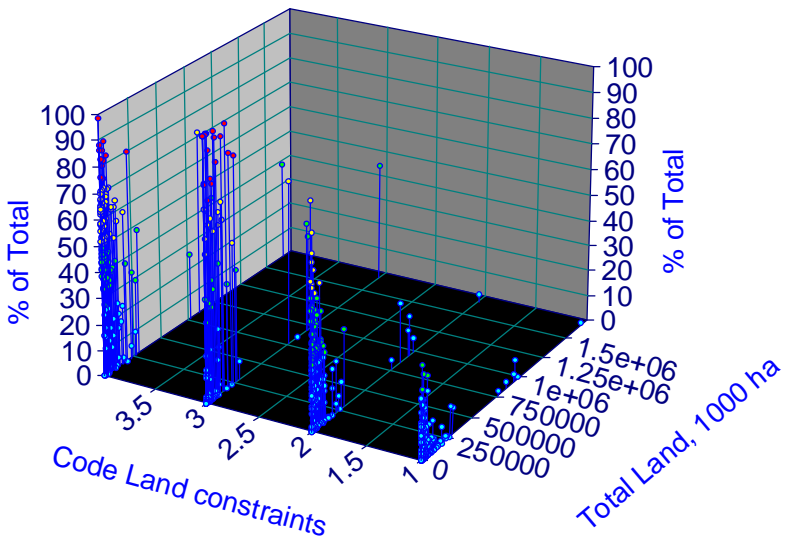

Рис. 1. Распределение активности GAEZ по общей площади стран и уровням земельных ограничений
Моделирование показало, что коэффициенты корреляции равны менее 0,25 . Поэтому адекватность моделей зависимости активности $\alpha$ от изменения площади территории страны $S$, причем по всем четырем уровням земельных ограничений, меньше 0,3. Из-за делаем вывод о том, что не существует закономерности типа $\alpha=f(S)$.

Таким образом, территория страны по площади не влияет на активность GAES. Однако с уменьшением территории до муниципалитетов на одном субъекте Российской Федерации были сильные закономерности $\alpha=f(S)$ с коэффициентом корреляции более $0,7[2,4,5,10,14-17,19]$. Поэтому на активность AEZ во многом влияет площадь территориального образования в рамках одной малой страны и муниципалитетов одного субъекта большой по площади страны.

Далее для каждого уровня земельных ограничений были приняты свои шкалы измерений по площади отдельных GAEZ (табл. 2). При этом $S_{1,2,3,4}=0,01 \alpha_{1,2,3,4} S$.

Таблица 2

Площади и земельные ограничения на богарных производствах сельхозкультур по 160 странам

\begin{tabular}{|c|c|c|c|c|c|c|c|c|c|}
\hline \multirow[t]{2}{*}{$\begin{array}{c}\text { Наименование } \\
\text { страны }\end{array}$} & \multirow[t]{2}{*}{$\begin{array}{c}\text { Общая } \\
\text { площадь } \\
S, 10^{3} \text { га }\end{array}$} & \multicolumn{2}{|c|}{$\begin{array}{c}\text { нет } \\
\text { ограничения }\end{array}$} & \multicolumn{2}{|c|}{$\begin{array}{c}\text { умеренное или } \\
\text { небольшое } \\
\text { ограничение }\end{array}$} & \multicolumn{2}{|c|}{$\begin{array}{c}\text { ограничения } \\
\text { по тяжелому } \\
\text { климату } \\
\end{array}$} & \multicolumn{2}{|c|}{$\begin{array}{c}\text { ограничения } \\
\text { по тяжелой } \\
\text { почве +местности }\end{array}$} \\
\hline & & $S_{1}$, т. га & $\alpha_{1}, \%$ & $S_{2}$, т. га & $\alpha_{2}, \%$ & $S_{3}$, т. га & $\alpha_{3}, \%$ & $S_{4}$, т. га & $\alpha_{4}, \%$ \\
\hline CANADA & 978404 & 5870 & 0,6 & 58704 & 6,0 & 494094 & 50,5 & 418757 & 42,8 \\
\hline UNITED STATES & 946837 & 79534 & 8,4 & 143919 & 15,2 & 350330 & 37,0 & 297307 & 31,4 \\
\hline BULGARIA & 11057 & 2433 & 22,0 & 4445 & 40,2 & 0 & 0,0 & 4168 & 37,7 \\
\hline BELARUS & 20615 & 103 & 0,5 & 12287 & 59,6 & 0 & 0,0 & 8225 & 39,9 \\
\hline HUNGARY & 9213 & 2349 & 25,5 & 2515 & 27,3 & 0 & 0,0 & 4358 & 47,3 \\
\hline
\end{tabular}


Почему же площадь страны не становится влияющим фактором? Ответ прост: границы каждой страны устанавливались веками по военно-политическим отношениям между народами. Поэтому площадь страны не является физической величиной, так как этот параметр территории зависит сильно от антропогенного влияния.

Далее рассмотрим модели по четырем уровням земельных ограничений, причем эти модели были получены по предельным возможностям программной среды.

Нет земельных ограничений. Первый уровень GAEZ по функции $\alpha_{1}=f\left(S_{1}\right)$ определяется (рис. 2) пятичленной формулой вида

$$
\begin{aligned}
& \alpha_{1}=\alpha_{11}+\alpha_{12}+\alpha_{13}+\alpha_{14}+\alpha_{15}, \\
& \alpha_{11}=4,34628 S_{1}^{9,68490} \exp \left(-24,19639 S_{1}^{0,14629}\right), \alpha_{12}=0.74481 S_{1}^{0,24162}, \\
& \alpha_{13}=A_{1} \cos \left(\pi S_{1} / p_{1}+2,51353\right), A_{1}=2,52821 \cdot 10^{-13} S_{1}^{4,17584} \exp \left(-0,024692 S_{1}^{0,60266}\right), \\
& p_{1}=533,85249+1,22945 S_{1}^{0,58907}, \alpha_{14}=A_{2} \cos \left(\pi S_{1} / p_{2}+4,84337\right), \\
& A_{2}=9,54691 \cdot 10^{-13} S_{1}^{4,13286} \exp \left(-0,010731 S_{1}\right), p_{2}=716,29755-0,074182 S_{1}^{0,99912}, \\
& \alpha_{15}=A_{3} \cos \left(\pi S_{1} / p_{3}+1,32313\right), A_{3}=8,39728 \cdot 10^{-19} S_{1}^{5,44142} \exp \left(-0,00012565 S_{1}^{1,16485}\right), \\
& p_{3}=14,01010 .
\end{aligned}
$$
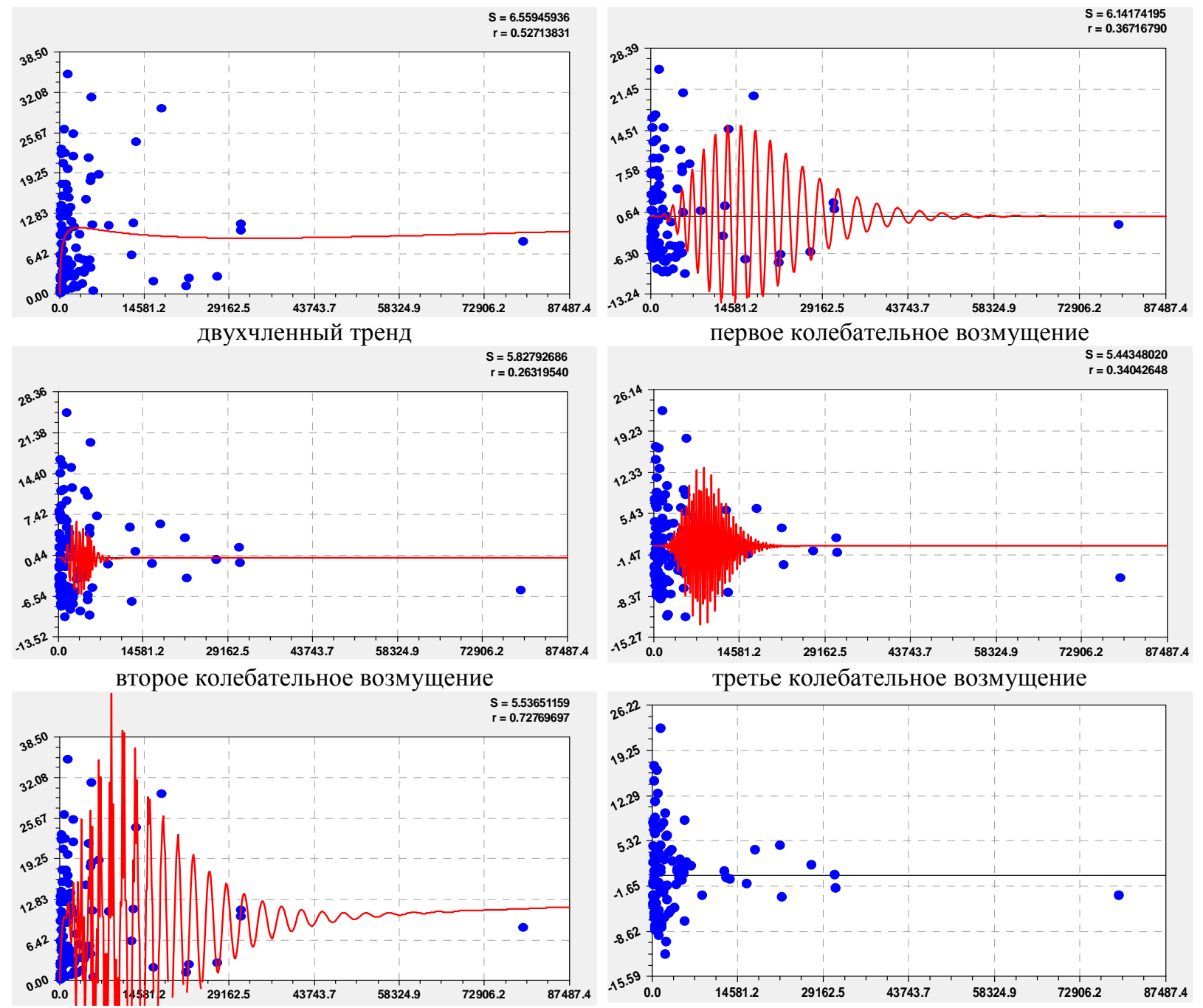

график общей пятичленной модели

остатки после пятичленной модели

Рис. 2. Графики составляющих модели распределения 160 стран по GAEZ «нет ограничений» (в верхнем правом углу графиков: $S$ - дисперсия; $r$ - коэффициент корреляции)

График пятичленной модели (2) получил коэффициент корреляции 0,7277. По уровням адекватности это значение больше 0,7 . Поэтому формула (2) относится к сильным факторным связям. При этом тренд содержит две составляющие. 
Умеренное или небольшое земельное ограничение. Второй уровень GAEZ по функции $\alpha_{2}=f\left(S_{2}\right)$ определяется также пятичленным уравнением (рис. 3). Для компактности записи вместо формулы типа (1) применяем матричную форму (табл. 3 ).
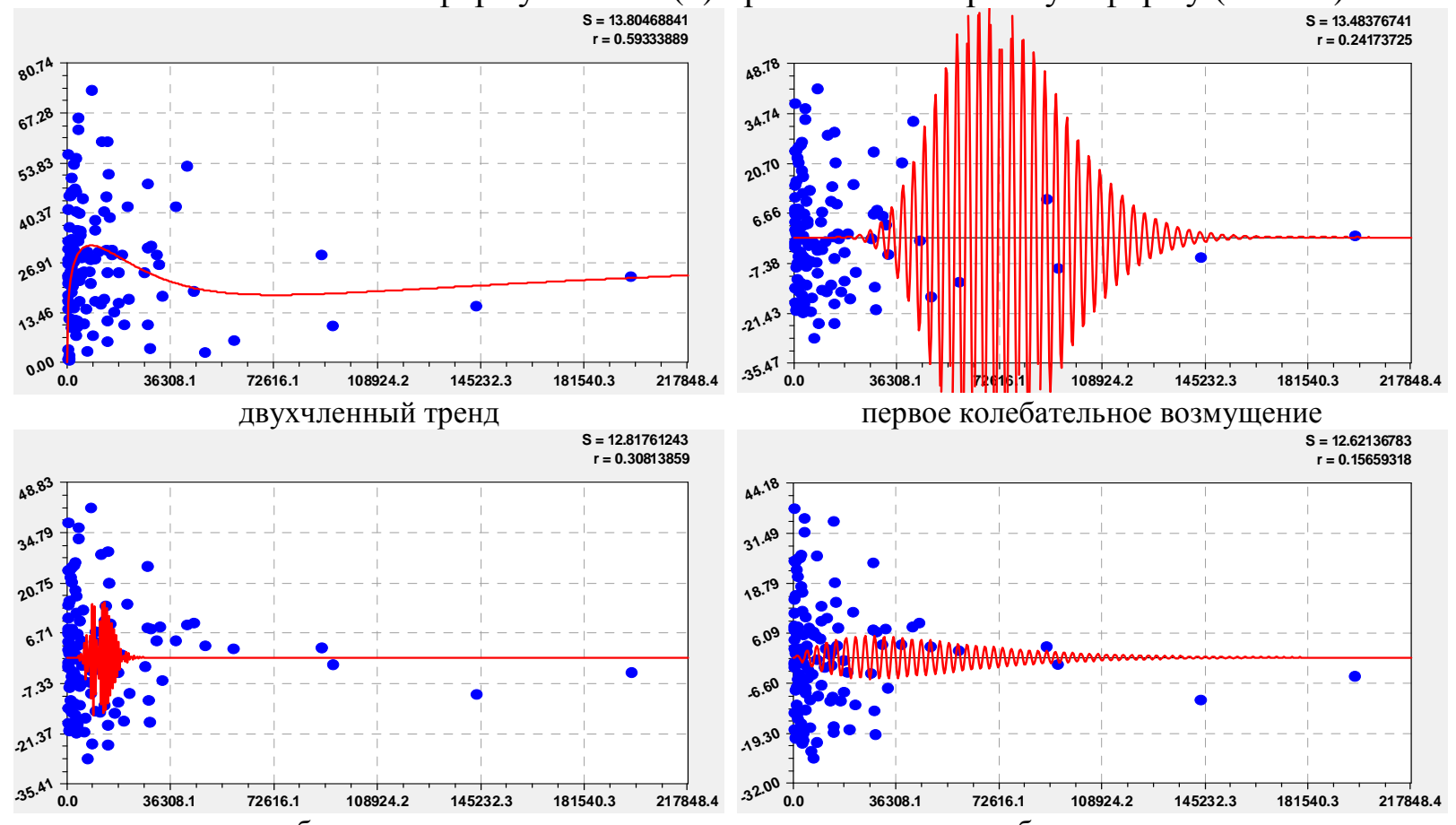
первое колебательное возмущение

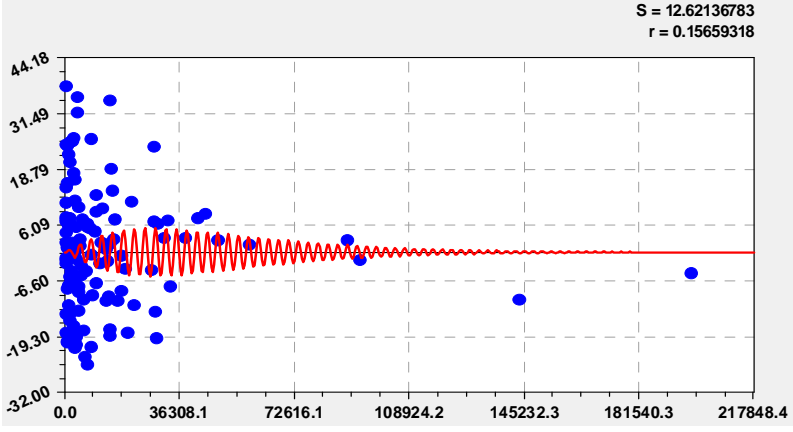
второе колебательное возмущение

$S=13.06610032$
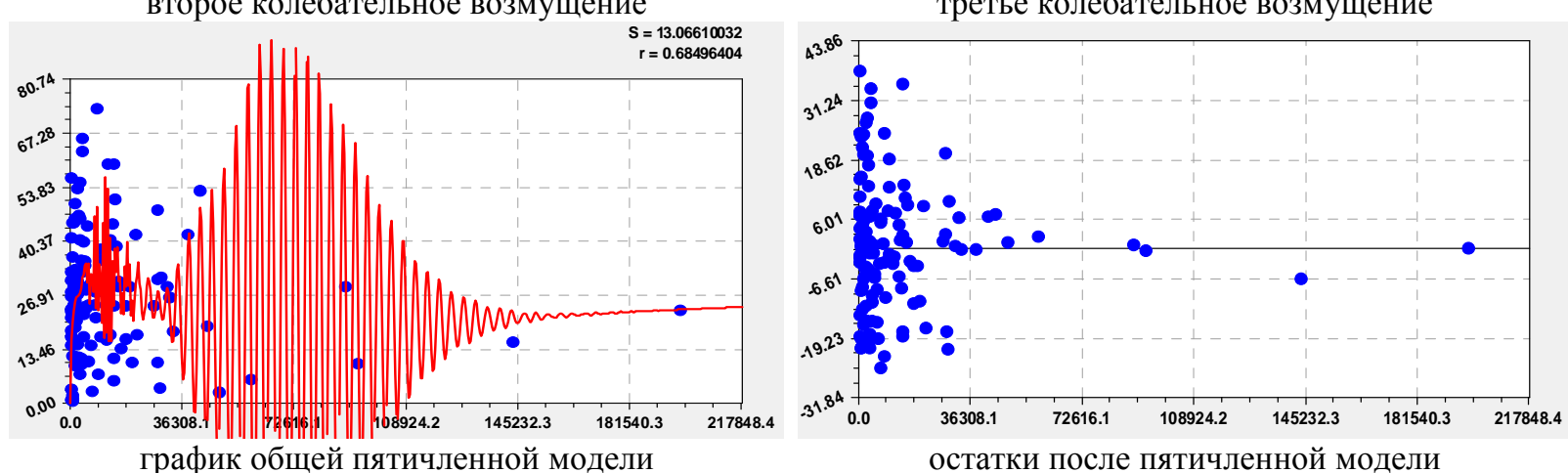

Рис. 3. Графики составляющих модели распределения 160 стран по GAEZ «умеренное ограничение»

Таблица 3

Параметры вейвлет-сигналов поведения GAEZ по уровням земельных ограничений

\begin{tabular}{|c|c|c|c|c|c|c|c|c|c|}
\hline & & & & & \multirow{2}{*}{\multicolumn{4}{|c|}{ Полупериод и сдвиг колебания (1) }} & \multirow{3}{*}{$\begin{array}{l}\text { Коэфф. } \\
\text { коррел. }\end{array}$} \\
\hline \multirow{2}{*}{$\begin{array}{c}\text { № } \\
i\end{array}$} & \multicolumn{4}{|c|}{ Амплитуда колебания (1) } & & & & & \\
\hline & $a_{1 i}$ & $a_{2 i}$ & $a_{3 i}$ & $a_{4 i}$ & $a_{5 i}$ & $a_{6 i}$ & $a_{7 i}$ & $a_{8 i}$ & \\
\hline \multicolumn{10}{|c|}{ Первый уровень GAEZ «Нет земельных ограничений» } \\
\hline 1 & 4,34628 & 9,68490 & 24,19639 & 0,14629 & 0 & 0 & 0 & 0 & \multirow{5}{*}{0,7277} \\
\hline 2 & 0,74481 & 0,24162 & 0 & 0 & 0 & 0 & 0 & 0 & \\
\hline 3 & $2,52821 \mathrm{e}-13$ & 4,17584 & 0,024692 & 0,60266 & 533,85249 & 1,22945 & 0,58907 & $-2,51353$ & \\
\hline 4 & $9,54691 \mathrm{e}-13$ & 4,13286 & 0,0010731 & 1 & 716,29755 & $-0,074182$ & 0,99912 & $-4,84337$ & \\
\hline 5 & $8,39728 \mathrm{e}-19$ & 5,44142 & 0,00012565 & 1,16485 & 14,01010 & 0 & 0 & $-1,32313$ & \\
\hline \multicolumn{10}{|c|}{ Второй уровень GAEZ «Умеренное или небольшое земельное ограничение» } \\
\hline 1 & 1,41150 & 0,36677 & $5,61871 \mathrm{e}-5$ & 1,00239 & 0 & 0 & 0 & 0 & \multirow{5}{*}{0,6850} \\
\hline 2 & 0,57448 & 0,30395 & 0 & 0 & 0 & 0 & 0 & 0 & \\
\hline 3 & $7,71513 e-46$ & 10,65248 & 0,00013834 & 1,00875 & 1847,2829 & 0,55794 & 0,41999 & 0,82266 & \\
\hline 4 & $2,57407 \mathrm{e}-31$ & 8,80401 & 0,00076312 & 1,00145 & 543,73190 & $-0,0052251$ & 0,99987 & $-1,56768$ & \\
\hline 5 & $-0,00041618$ & 1,05949 & $5,82141 \mathrm{e}-5$ & 0,97204 & 1763,5298 & $-0,0069356$ & 0,86158 & $-0,93324$ & \\
\hline \multicolumn{10}{|c|}{ Третий уровень GAEZ «Земельные ограничения по тяжелому климату» } \\
\hline 1 & 2,06819 & 0,34075 & $2,12801 \mathrm{e}-5$ & 0,85168 & 0 & 0 & 0 & 0 & \multirow[t]{4}{*}{0,9016} \\
\hline 2 & $1,23468 \mathrm{e}-5$ & 1,08059 & 0 & 0 & 0 & 0 & 0 & 0 & \\
\hline 3 & $-2,84497$ & 0,17296 & $2,00000 \mathrm{e}-5$ & 0,90878 & 1347,6812 & 0,020033 & 1,05702 & 0,28532 & \\
\hline 4 & 0,054034 & 0,64550 & $4,00000 \mathrm{e}-5$ & 0,97104 & 1187,1409 & 0,00029249 & 1,07566 & 0,70797 & \\
\hline
\end{tabular}




\begin{tabular}{|c|c|c|c|c|c|c|c|c|c|}
\hline \multirow{2}{*}{$\begin{array}{c}\text { № } \\
i\end{array}$} & \multicolumn{4}{|c|}{ Амплитуда колебания (1) } & \multicolumn{4}{|c|}{ Полупериод и сдвиг колебания (1) } & \multirow{3}{*}{$\begin{array}{l}\text { Коэфф. } \\
\text { коррел. }\end{array}$} \\
\hline & $a_{1 i}$ & $a_{2 i}$ & $a_{3 i}$ & $a_{4 i}$ & $a_{5 i}$ & $a_{6 i}$ & $a_{7 i}$ & $a_{8 i}$ & \\
\hline 5 & 3,08756 & 0,26022 & 0,056767 & 0,28583 & 580,58900 & 0,79362 & 0,84997 & 4,90838 & \\
\hline \multicolumn{10}{|c|}{ Четвертый уровень GAEZ «Земельные ограничения по тяжелой почве и трудной местности» } \\
\hline 1 & 23,57306 & 0,084552 & $1,68042 \mathrm{e}-5$ & 0,86349 & 0 & 0 & 0 & 0 & \multirow{5}{*}{0,5934} \\
\hline 2 & $5,50943 \mathrm{e}-5$ & 1 & 0 & 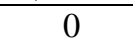 & 0 & 0 & 0 & 0 & \\
\hline 3 & $-1,30289 \mathrm{e}-20$ & 4,18607 & $2,00000 \mathrm{e}-5$ & 0,93890 & 11688,2120 & 0,00074183 & 0,95627 & $-3,80781$ & \\
\hline 4 & $8,16287 \mathrm{e}-25$ & 6,07996 & $5,00000 \mathrm{e}-5$ & 1,09643 & 99,87808 & 0 & 0 & 0,49242 & \\
\hline 5 & $-4,43864 \mathrm{e}-10$ & 2,65 & 0,00010933 & 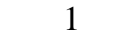 & 472,15412 & $-0,00023813$ & 1 & 1,23749 & \\
\hline
\end{tabular}

Земельные ограничения по тяжелому климату. Третий уровень GAEZ по функции $\alpha_{3}=f\left(S_{3}\right)$ определяется (рис. 4) также пятичленным уравнением (табл. 3) с коэффициентом корреляции $0,9016$.
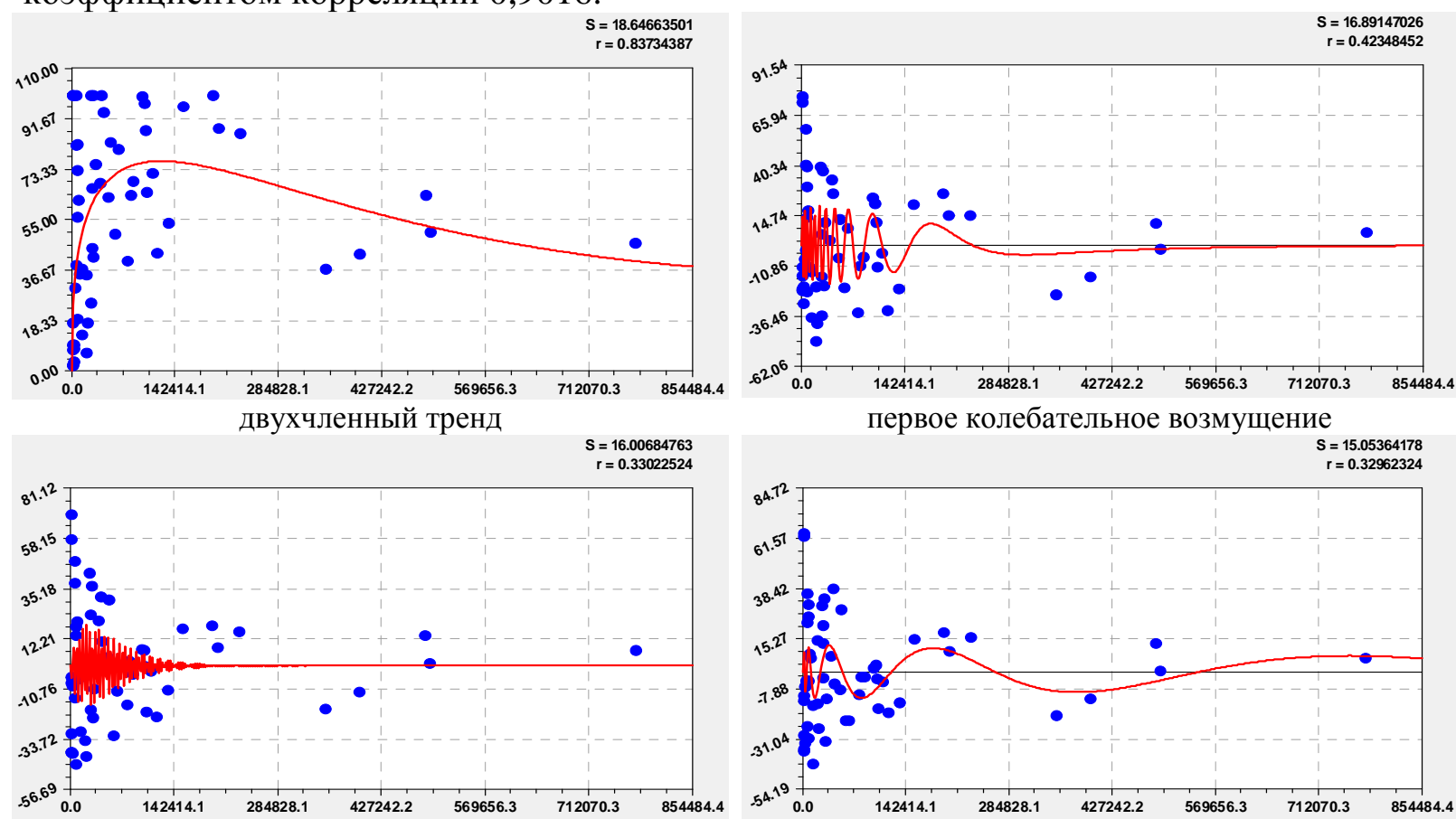

второе колебательное возмущение

$S=15.42673931$
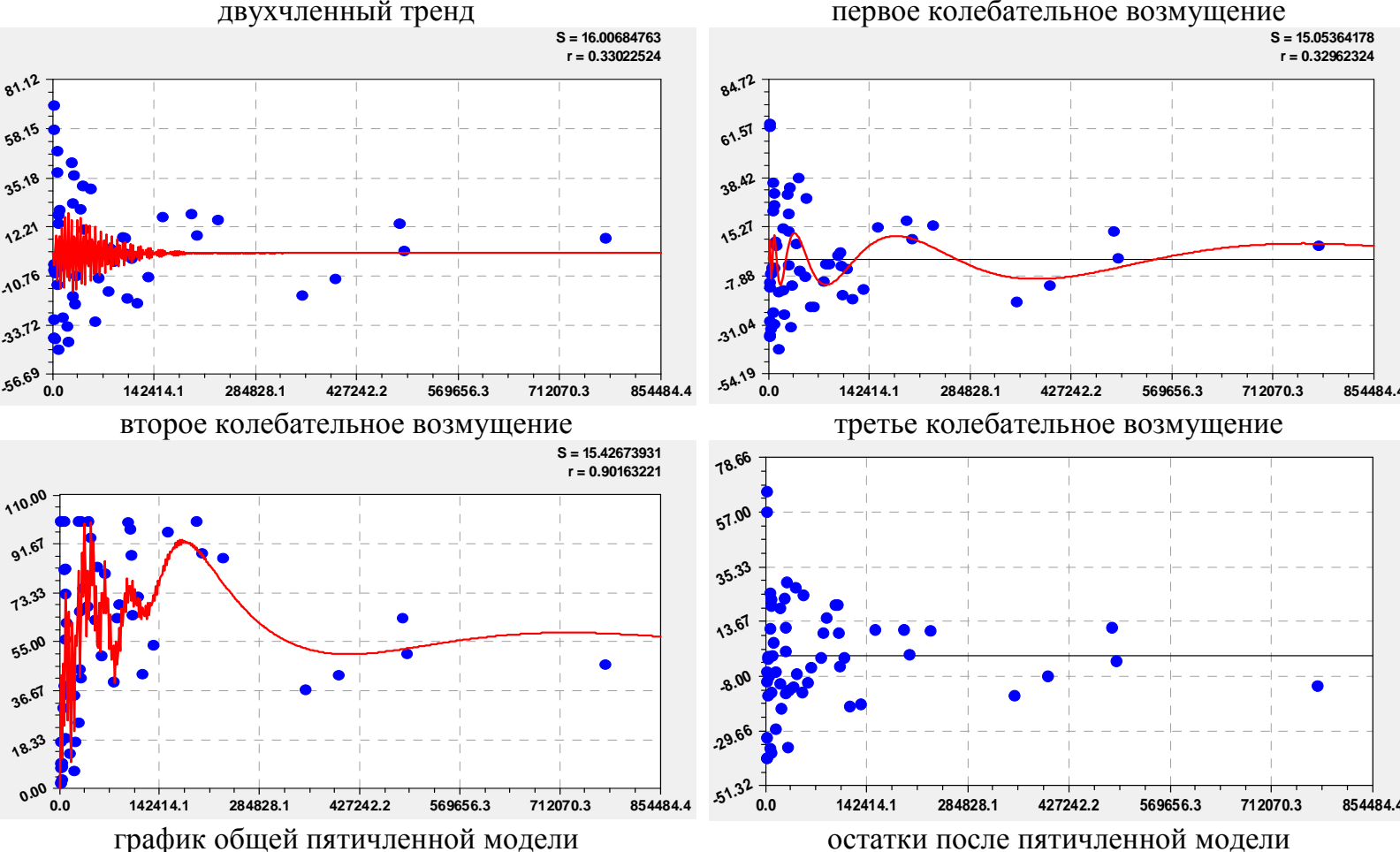

третье колебательное возмущение

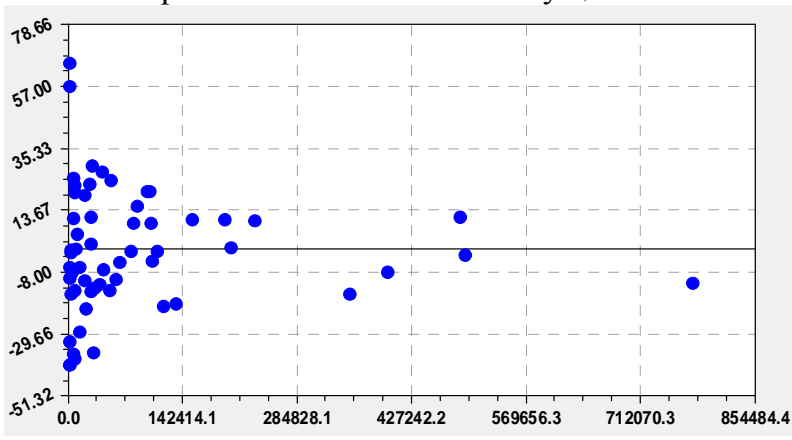

остатки после пятичленной модели

Рис. 4. Графики составляющих модели распределения 160 стран по GAEZ «ограничение по климату»

Такая высокая адекватность модели указывает на то, что климат пока менее нарушен человеком, чем это произошло по первым двум земельным ограничениям. Иначе говоря, климат еще изменяется больше по естественным законам, а не по человеку. Поэтому для учета климатических факторов в технологию GAEZ нужно ввести модуль моделирования динамики (например, глобальной температуры за тысячи лет).

Земельные ограничения по тяжелой почве и трудной местности. Четвертый уровень GAEZ по функции $\alpha_{4}=f\left(S_{4}\right)$ определяется (рис. 5) с наименьшей адекватностью 0,5934 (средняя теснота факторной связи). Этот уровень ограничений не зависит от человека, а больше всего зависит от климата, рельефа и положения оси Земли. 

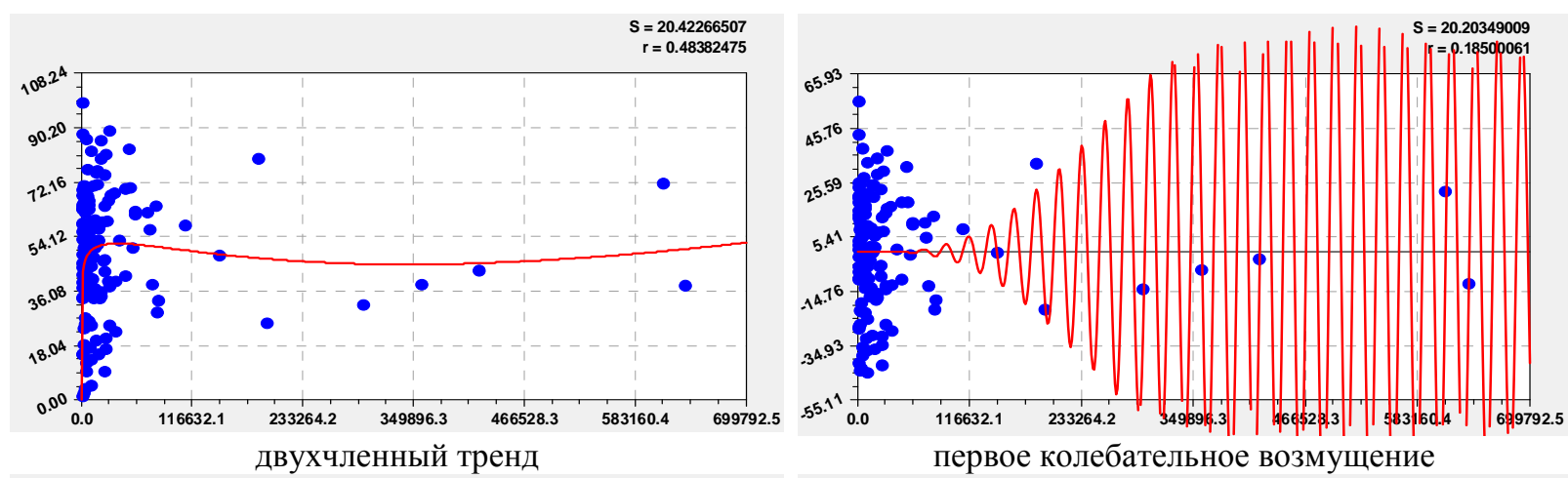

вухчленный тренд

первое колебательное возмущение

$=0.25151917$

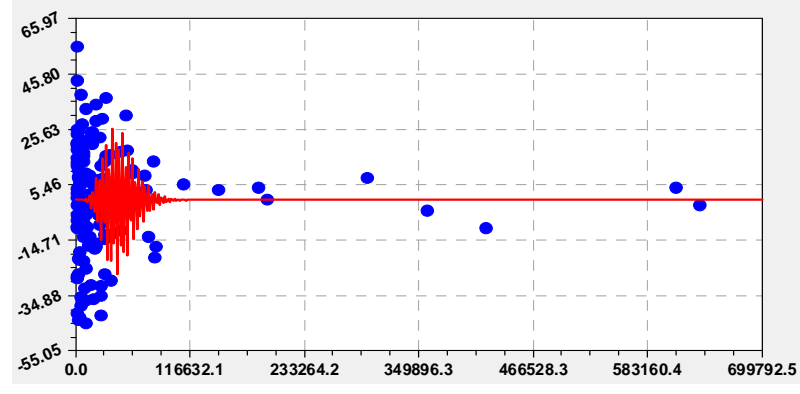

второе колебательное возмущение
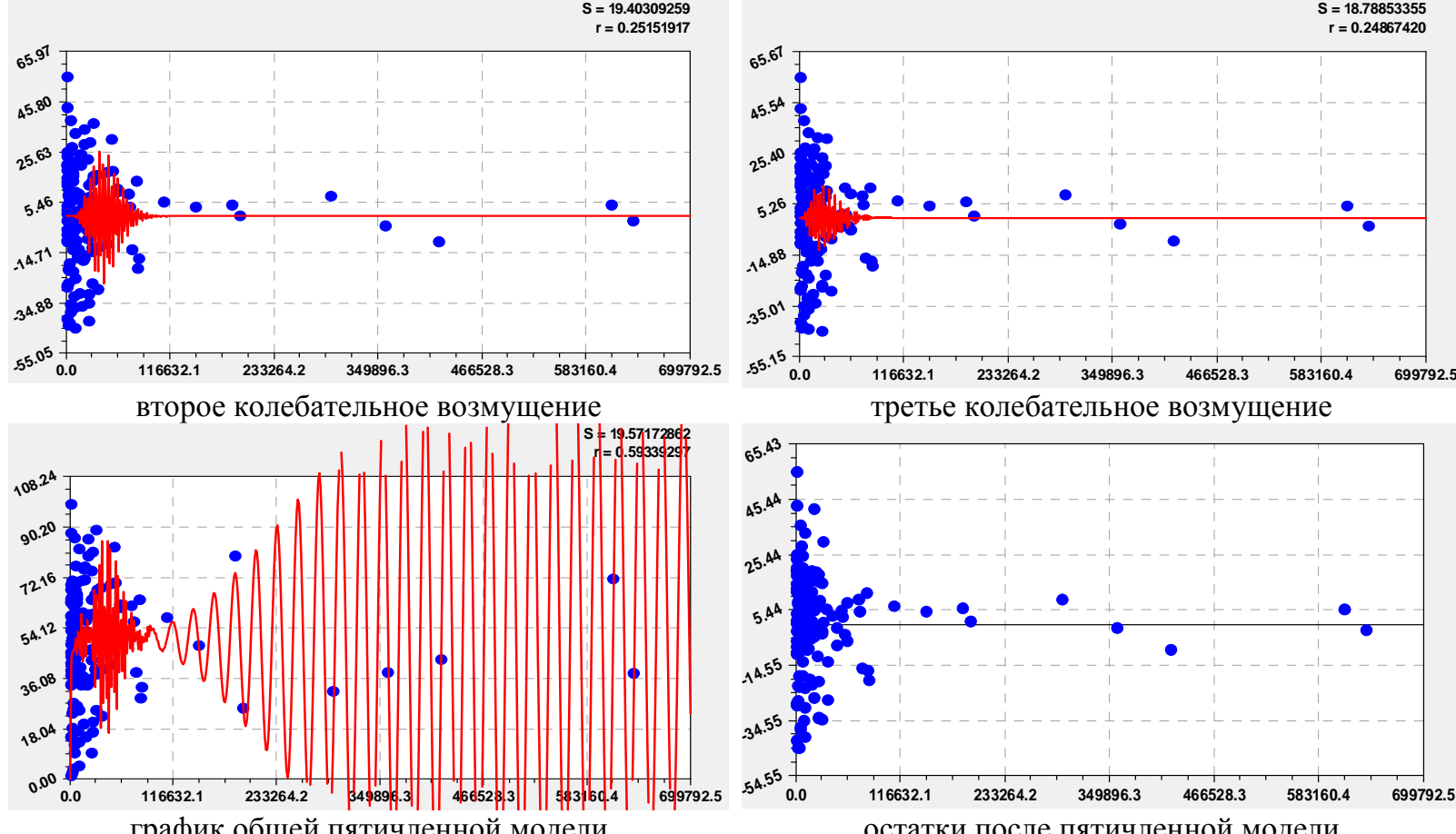

третье колебательное возмущение

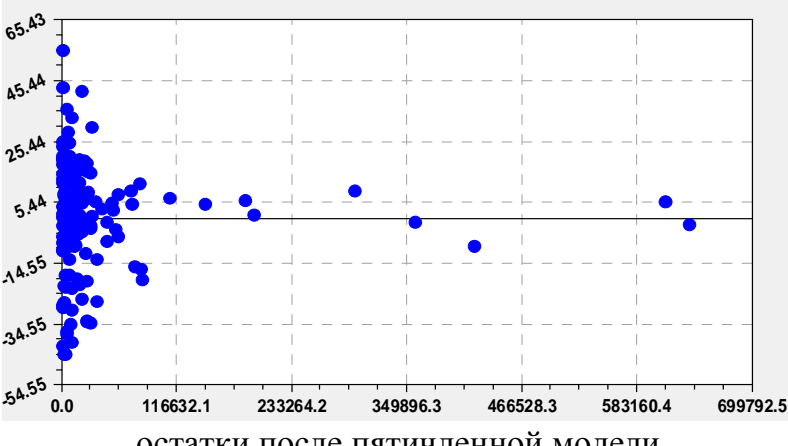

Рис. 5. Графики составляющих распределения 160 стран по GAEZ «ограничение по почве и местности»

Для сравнения запишем четыре уровня по пяти членам общего уравнения.

Сравнение моделей уровней земельных ограничений. В таблице 4 приведены сводные результаты статистического моделирования.

Таблица 4

Коэффициенты корреляции модели по наращиванию количества составляющих

\begin{tabular}{|l|c|c|c|c|c|}
\hline \multicolumn{1}{|c|}{ Уеменни } & \multicolumn{5}{|c|}{ Количество членов в модели } \\
\cline { 2 - 6 } & 1 & 2 & 3 & 4 & 5 \\
\hline 1. Нет земельных ограничений & $0,5105 / 100$ & $0,5271 / 103$ & $0,6257 / 123$ & $0,6614 / 130$ & $0,7277 / 143$ \\
\hline $\begin{array}{l}\text { 2. Умеренное или небольшое } \\
\text { земельное ограничение }\end{array}$ & $0,5744 / 100$ & $0,5933 / 103$ & $0,6252 / 109$ & $0,6723 / 117$ & $0,6850 / 119$ \\
\hline $\begin{array}{l}\text { 3. Земельные ограничения } \\
\text { по тяжелому климату }\end{array}$ & $0,8368 / 100$ & $0,8373 / 100$ & $0,8695 / 104$ & $0,8848 / 106$ & $0,9016 / 108$ \\
\hline $\begin{array}{l}\text { 4. Земельные ограничения по } \\
\text { тяжелой почве и трудной местности }\end{array}$ & $0,4754 / 100$ & $0,4838 / 102$ & $0,5118 / 108$ & $0,5559 / 117$ & $0,5934 / 125$ \\
\hline
\end{tabular}

Как видно из данных таблицы 4, волновые закономерности значимы, прежде всего, для первого уровня земельных ограничений. Как правило, колебания возникают изза антропогенного воздействия. Причем, чем больше воздействие человека на природную среду, тем сильнее колебания объектов, в нашем случае GAEZ. Наименьшие возмущения имеет третий уровень земельных ограничений. Поэтому земельные ограничения по климату можно оценивать только по первой составляющей в виде формулы

$$
\alpha_{3} \approx a_{31}=2,06819 S_{3}^{0,34075} \exp \left(-2,12801 \cdot 10^{-5} S_{3}^{0,85168}\right) .
$$


При этом, как правило, первый член по биотехническому закону [3-20] характеризует естественное поведение природных объектов, то есть без учета влияния человека.

На рисунке 6 показаны графики первых составляющих по формулам:

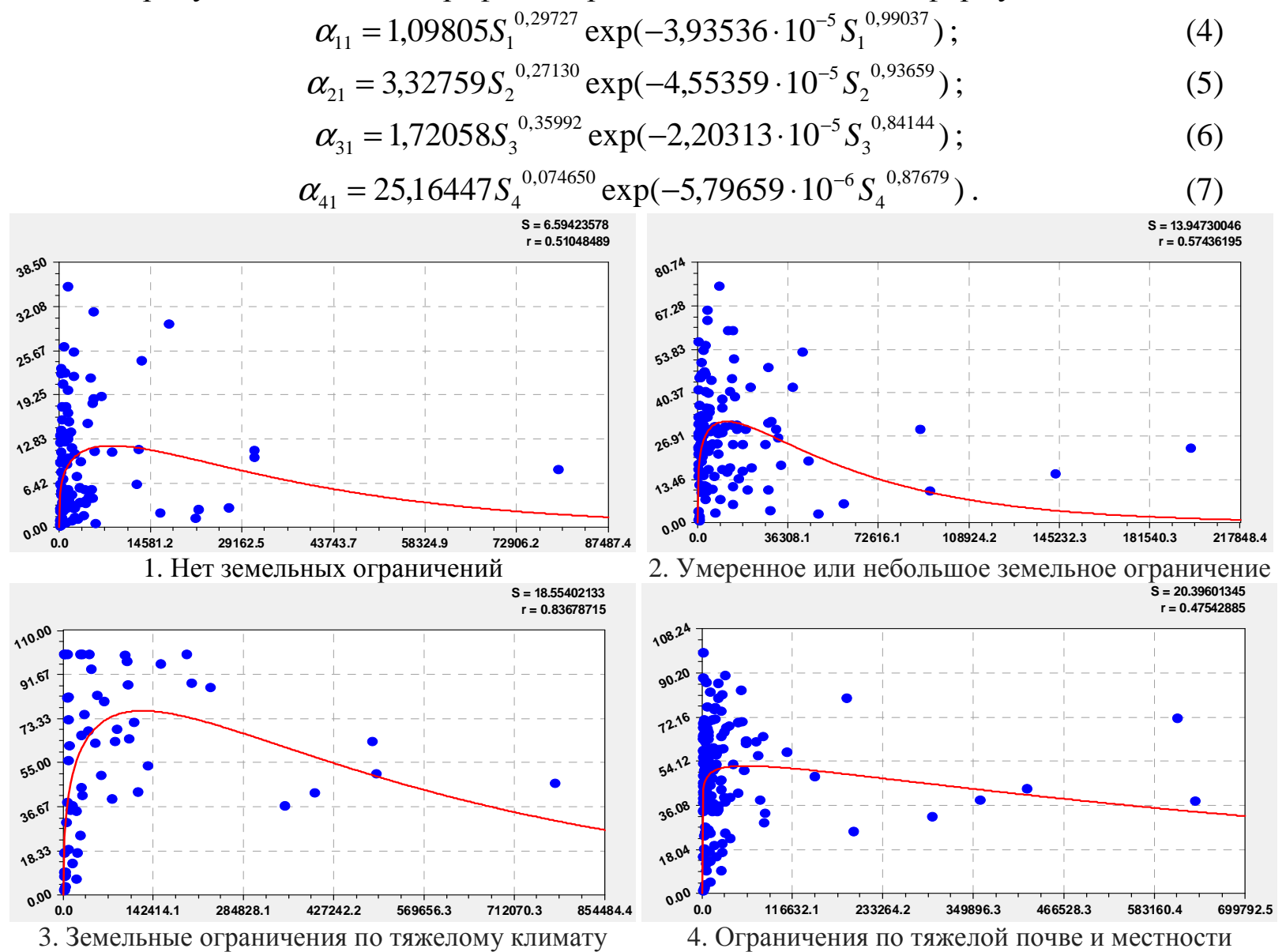

3. Земельные ограничения по тяжелому климату

4. Ограничения по тяжелой почве и местности

Рис. 6. Графики первых членов формул распределения 160 стран по уровням земельных ограничений

Эти формулы пригодны для ориентировочных расчетов, а также для сравнения различных группировок стран (например, по континентам и т.д.).

Влияние уровней ограничений. Из данных таблицы 4 видно, что по мере роста ранга уровня $R$ земельных ограничений коэффициент корреляции $r$ изменяется также по биотехническому закону. В таблице 5 даны исходные данные для моделирования.

Таблица 5

Коэффициенты корреляции модели по рангам уровней земельных ограничений

\begin{tabular}{|l|c|c|c|c|c|}
\hline \multicolumn{1}{|c|}{ Распределение уровней } & \multicolumn{5}{|c|}{ Количество членов в модели } \\
\cline { 2 - 7 } земельных ограничений по рангам & 1 & 2 & 3 & 4 & 5 \\
\hline 0. Сверх идеальная GAEZ для сельского хозяйства & 0 & 0 & 0 & 0 & 0 \\
\hline 1. Нет земельных ограничений & 0,5105 & 0,5271 & 0,6257 & 0,6614 & 0,7277 \\
\hline 2. Умеренное или небольшое земельное ограничение & 0,5744 & 0,5933 & 0,6252 & 0,6723 & 0,6850 \\
\hline 3. Земельные ограничения по тяжелому климату & 0,8368 & 0,8373 & 0,8695 & 0,8848 & 0,9016 \\
\hline 4. Земельные ограничения по тяжелой почве и местности & 0,4754 & 0,4838 & 0,5118 & 0,5559 & 0,5934 \\
\hline 5. Критическая потеря GAEZ из-за изменения планеты & 0 & 0 & 0 & 0 & 0 \\
\hline
\end{tabular}

Математически ранги определяются всегда, начиная с нуля. После идентификации были получены следующие статистические модели (рис. 7):

- один член биотехнической закономерности

$$
r_{1}=4,95204 R^{1,23021} \exp (-0,014794 R)-4,43846 R^{1,25225} ;
$$

- два члена биотехнической закономерности

$$
r_{2}=5,22644 R^{1,20396} \exp (-0,014441 R)-4,69253 R^{1,22599} ;
$$

- три члена биотехнической закономерности 


$$
r_{3}=7,70094 R^{1,08326} \exp (-0,011315 R)-7,07306 R^{1,10069} ;
$$

- четыре члена биотехнической закономерности

$$
r_{4}=8,40769 R^{1,06690} \exp (-0,010880 R)-7,74030 R^{1,08414} ;
$$

- пять членов биотехнической закономерности (рис. 8)
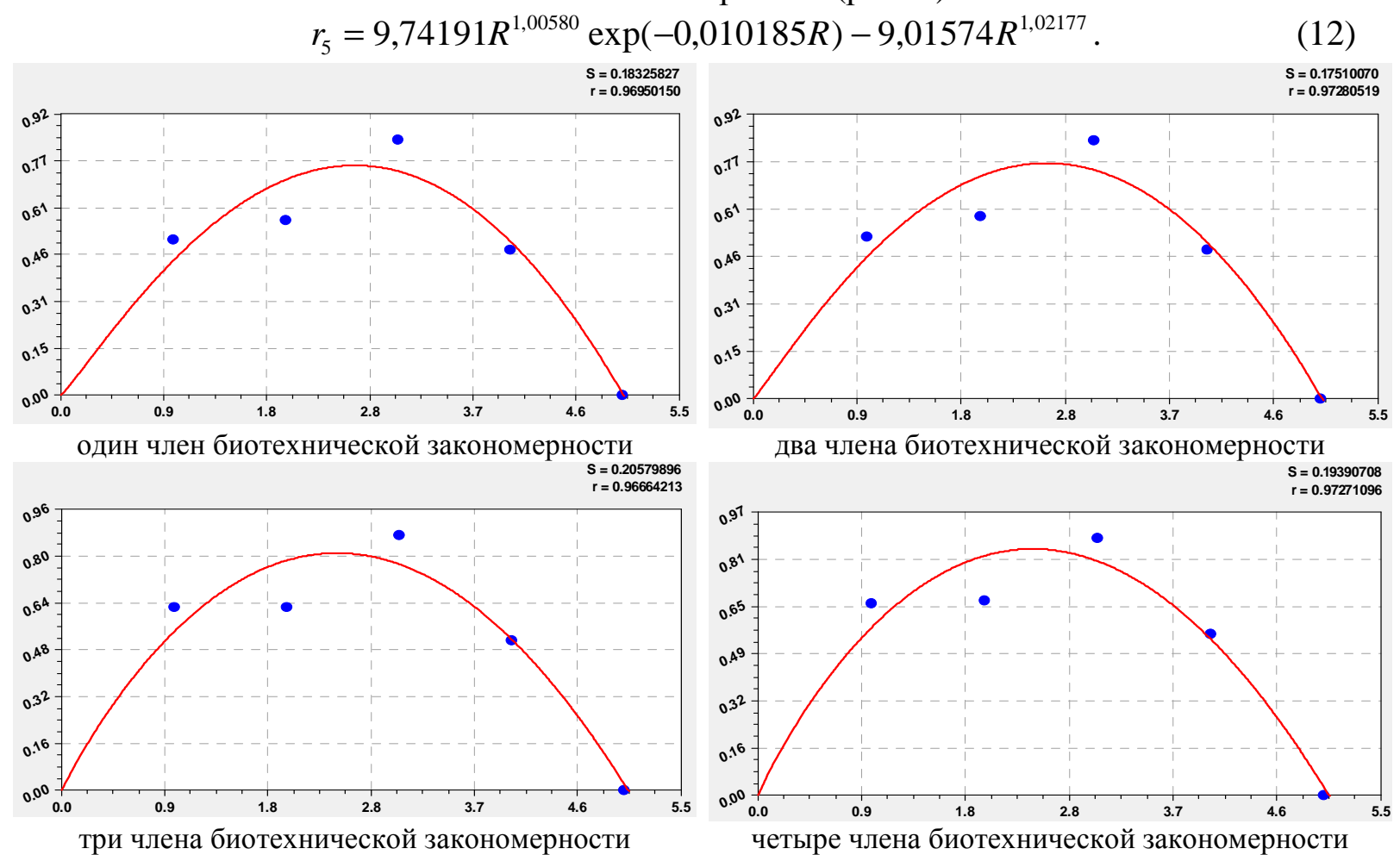

Рис. 7. Графики влияния рангов уровней земельных ограничений на адекватность модели

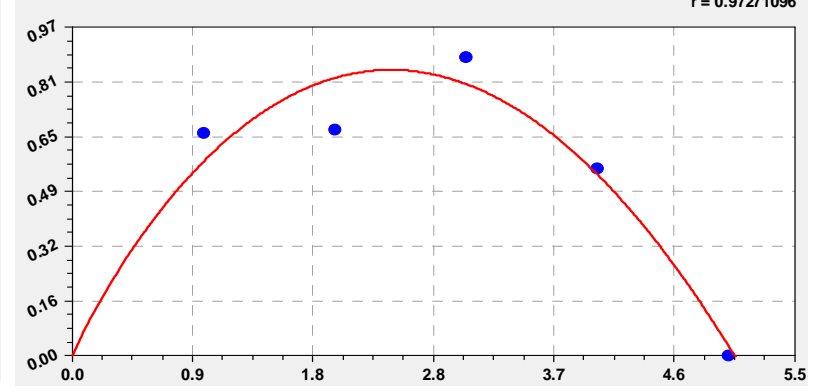

четыре члена биотехнической закономерности

Высокая адекватность формул (коэффициент корреляции выше 0,95) позволяет утверждать о добротности распределения земель [1] по четырем уровням ограничений.

Проверка классификации уровней земельных ограничений. Из графиков на рисунке 7 видно, что относительно уровней имеются колебания. Доля волновой составляющей к тренду показывает добротность классификации по уровням ограничений.

После идентификации была получена (рис. 8) трехчленная формула

$$
\begin{aligned}
& r_{5}=9,74200 R^{1,00580} \exp (-0,010185 R)-9,01590 R^{1,02177}+A \cos (\pi R / p-2,33752), \\
& A=0,37943 R^{2,24766} \exp (-1,15918 R), p=1,00350+0,077057 R .
\end{aligned}
$$
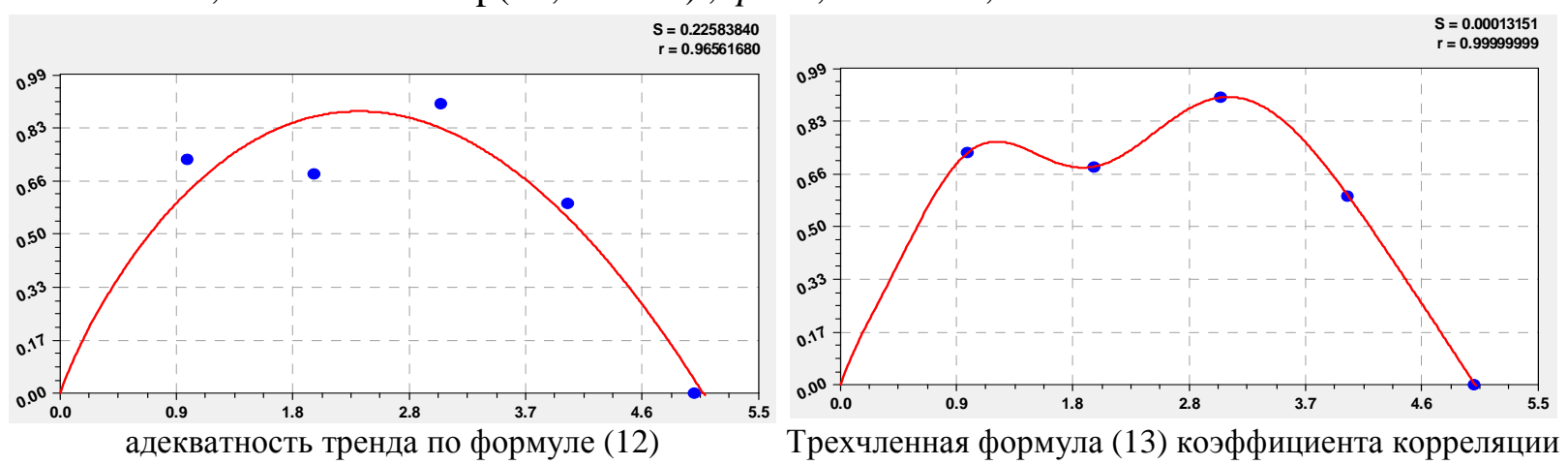

Рис. 8. Графики влияния рангов уровней ограничений на адекватность модели из пяти членов

Проверка классификации выполняется по полупериоду $p=1,00350+0,077057 R$.

Заключение. Для оценки земельных ресурсов глобальные агроэкологические зоны (GAEZ) дают стройные математические формулы распределения по уровням земельных ограничений. При этом за влияющую переменную принимается площадь GAEZ, а не площадь территории страны. Зависимой переменной (показателем) стано- 
вится доля GAEZ в общей площади территории страны.

В условиях России вопросы территориального землепользования во многом отстают от идеологии глобальных агроэкологических зон, практически значительно обеспеченных для многих стран материалами геоинформационного картографирования всей поверхности суши Земли. Из 160 стран Российская Федерация остается как бы в стороне из-за отсутствия отечественных географических информационных систем.

В связи с этим предлагается совместить технологию GAEZ с отечественным земельным кадастром с семью категориями земель. Это позволило бы резко поднять на более качественный уровень информационного обеспечения территориальное землепользование и в субъектах России. При этом предлагаемая методология статистического моделирования вполне позволяет объединить российское землеустройство и кадастры с мировыми достижениями в технологии GAEZ.

\section{Литература}

1. Global Agro-ecological Assessment for Agriculture in the 21st Century: Methodology and Results. G̈unther Fischer, Harrij van Velthuizen, Mahendra Shah, Freddy Nachtergaele. International Institute for Applied Systems Analysis, Laxenburg, Austria. Food and Agriculture Organization of the United Nations. Viale delle Terme di Caracalla. Rome, Italy, 2002. Url: http://webarchive.iiasa.ac.at/Research/LUC/SAEZ/index.html.

2. Арзамасцев А.Д., Мазуркин П.М., Максимец Н.В. Факторный анализ сельскохозяйственного производства. Йошкар-Ола: МарГТУ, 2009. 388 с.

3. Мазуркин П.М. Биокаркас территории: учеб. пос. с грифом УМО РАЕ. Йошкар-Ола: Поволжский ГТУ, 2013. 156 с.

4. Мазуркин П.М. Биотехнические закономерности факторов сельхозпроизводства // Современные наукоемкие технологии. 2009. № 7. С.20-29.

5. Мазуркин П.М. Геоэкология: Закономерности современного естествознания: научное изд. Йошкар-Ола: МарГТУ, 2006. 336 с.

6. Мазуркин П.М. Закономерности простых чисел. Германия: Palmarium Academic Publishing, 2012. $280 \mathrm{c}$.

7. Мазуркин П.М. Идентификация статистических устойчивых закономерностей // Наука и мир: международный научный журнал. 2013. № 3(3). С.28-33.

8. Мазуркин П.М. Коррелятивная вариация: учеб. пос. с грифом УМО РАЕ. Йошкар-Ола: Поволжский ГТУ, 2013. 120 с.

9. Мазуркин П.М. Лесоаграрная Россия и мировая динамика лесопользования: научное издание. Йошкар-Ола: МарГТУ, 2007. 334 с.

10. Мазуркин П.М. Оценка экологического неравновесия сельских и городских территорий по площади растительного покрова // Современные проблемы науки и образования. 2009. № 4. С.82-92.

11. Мазуркин П.М. Прошлое, современное состояние и перспективы лесоаграрной России // Современные проблемы науки и образования. 2009. № 4. С.93-112.

12. Мазуркин П.М. Решение 23-ой проблемы Гильберта Междисциплинарные исследования в области математического моделирования и информатики. Матер. 3-й научно-прак. internet-конф. Ульяновск: SIMJET, 2014. С 269-277.

13. Мазуркин П.М. Распределение пробных площадей березняков Северной Евразии и факторный анализ показателей // Леса России в XXI веке: Матер. пятой межд. научно-практ. Интернет-конф. (октябрь 2010). СПб.: ЛТА, 2010. С. 93-108.

14. Мазуркин П.М. Территориально-экологическое неравновесие Мариинско-Посадского района // Сб. статей научн. практ. конф. «Проблемы экологии и лесопользования в современных условиях». Йошкар-Ола: МарГТУ, 2010. С.84-89.

15. Мазуркин П.М. Территориальный экологический баланс. Йошкар-Ола: МарГТУ, 2011.72 с.

16. Мазуркин П.М. Факторные связи и показатели сельхозпроизводства // Современные наукоемкие технологии. 2009. № 7. С.42-52.

17. Мазуркин П.М. Экологический баланс территории: учеб. пос. с грифом УМО РАЕ. ЙошкарОла: Поволжский ГТУ, 2013. 152 с.

18. Мазуркин П.М., Фадеев А.Н. Геоинформационные системы земельного кадастра, лесного реестра и особо охраняемых территорий // Современные проблемы науки и образования. 2009. № 4. С.69-75.

19. Мазуркин П.М., Фадеев А.Н. Закономерности распределения земельного фонда (на примере Республики Марий Эл): научное издание. Йошкар-Ола: МарГТУ, 2006. 127 с.

20. Мазуркин П.М., Филонов А.С. Математическое моделирование. Идентификация однофакторных статистических закономерностей: учебное пособие. Йошкар-Ола: МарГТУ, 2006. 292 с. 